\title{
A method for typing strains of Legionella pneumophila serogroup 1 by analysis of restriction fragment length polymorphisms
}

\author{
N. A. SAUNDERS, T. G. HARRISON, ARUNI HATHTHOTUWA, NAFISA KACHWALLA and
}

A. G. TAYLOR

Legionella Reference Unit, DMRQC, Central Public Health Laboratory, 61 Colindale Avenue, London NW9 5 HT

\begin{abstract}
Summary. A restriction fragment length polymorphism (RFLP) typing method for Legionella pneumophila serogroup 1 was developed. The method depended upon the use of cloned EcoR1 fragments from L. pneumophila (Knoxville-1) probing Ncil restriction fragments of chromosomal DNA. Examination of strains of $L$. pneumophila which were apparently unrelated showed that inter-strain RFLPs were common, and these formed the basis of the typing scheme. The technique was found to be highly reproducible and discriminatory. When the RFLP data were compared to that obtained by monoclonal antibody (MAb) subgrouping both methods of strain differentiation gave consistent results. The isolates examined by either method were also sub-divided by the alternative technique. The analysis of RFLPs by cloned probes should be of considerable epidemiological value.
\end{abstract}

\section{Introduction}

Legionnaires' disease (LD), a sometimes fatal systemic illness of which the primary clinical feature is pneumonia, is caused by Legionella pneumophila which is a ubiquitous, aquatic, gram-negative bacterium. Various methods can be used to distinguish between strains of $L$. pneumophila for epidemiological purposes. The techniques employed include serogrouping, monoclonal antibody (MAb) subgrouping (Joly et al., 1986), isoenzyme analysis (Selander et al., 1985) and restriction endonuclease digest analysis (van Ketel et al., 1984). Each technique has advantages and disadvantages in discrimination, reproducibility and ease of use. Serogrouping can divide the species into at least 14 serogroups (Benson et al., 1988), but the majority of cases of LD are caused by serogroup 1 strains (Bartlett et al., 1986). MAb subgrouping is able to sub-divide serogroup 1 strains, however only a small number of such subgroups have been observed. Isoenzyme analysis is able to achieve high discrimination between strains but is labour intensive and specialised. Analysis of total restriction endonuclease digest patterns reveals subtle differences between strains but these are difficult to interpret. Furthermore, a high degree of reprodu-

Received 15 May 1989; accepted 14 July 1989. cibility is necessary but is technically difficult to achieve.

We have previously reported a typing method based on the use of cloned biotinylated DNA probes for the analysis of restriction fragment length polymorphisms (RFLPs) (in sequences complementary to the probe) in the $L$. pneumophila genome (Saunders et al., 1987). This paper presents the results of an evaluation of the typing method.

\section{Materials and methods}

\section{Bacterial strains}

Isolates of $L$. pneumophila serogroup 1 were obtained during 1979-1988 from Europe, North America, Asia and Australia. Their identity was confirmed on the basis of nutritional, biochemical and serological characteristics (Harrison and Taylor, 1988). The strains, which were stored on glass beads at $-70^{\circ} \mathrm{C}$, were recovered by subculture on to BCYE and incubated for $72 \mathrm{~h}$ at $37^{\circ} \mathrm{C}$ before being harvested in saline and pelleted by centrifugation. Strains subjected to serial subcultivation were replated after growth for $48-72 \mathrm{~h}$.

For this study, 172 consecutive strains were examined. The isolates were divided into two groups (either 'related' or 'unrelated') according to their source of origin. Strains were considered to be 'related' if they were isolated, within the same year, from patients with a possible or confirmed common source of infection. Environmental isolates were placed into the 'related' group if they were 
cultured from the same locality as any other environmental or clinical strain providing the original specimens were taken within a 12-month period.

Data available on the source of some strains were incomplete; for example, in a few instances only the country of origin was known. Such strains were included in the 'unrelated' group if there was a possible geographical association with a strain isolated in the same country.

Amongst isolates that were 'related', the first of them to be examined in this study was also included in the group of 'unrelated' strains. The 100 strains in the 'unrelated' group were used to estimate the discrimination of the method (table I). Groups of 'related' strains with a known epidemiological assocation were examined to evaluate its reproducibility (table II).

\section{RFLP-typing}

Preparation of Southern blots. DNA was extracted from the bacterial pellets by an isopropanol precipitation method (Owen and Borman, 1987) and digested with $\mathrm{Ncil}$. The restriction fragments were subjected to agarose $(1 \%)$ gel electrophoresis and blotted on to nylon filters as described previously (Saunders et al., 1988b), except that transfer to nylon membranes was achieved with the aid of a Vacublot apparatus (Anderman) with $10 \times \mathrm{SSC}$ as transfer buffer.

For some strains an alternative method for the rapid extraction of DNA was used. Bacterial cells (25-50 $\mu 1$ pellet volume in a microcentrifuge tube) were treated with $100 \mu \mathrm{l}$ of a solution of lysozyme $2 \mathrm{mg} / \mathrm{ml}$ in sucrose $25 \%, 50 \mathrm{~mm}$ Tris/ $\mathrm{HCl}, \mathrm{pH} 8.0$. After incubation for 10 min at $20^{\circ} \mathrm{C}$, the lysozyme-treated cells were dissolved by addition of $200 \mu \mathrm{l}$ of $5 \mathrm{M}$ guanidine isothiocyanate, $0 \cdot 1 \mathrm{M}$ EDTA, $\mathrm{pH} 7.0$, and $150 \mu \mathrm{l}$ of $7.5 \mathrm{M}$ ammonium acetate was added to the cleared solution. The lysate was emulsified with an equal volume of chloroform:isoamyl alcohol $(24: 1, \mathrm{v}: \mathrm{v})$ and the phases were separated by microfuge centrifugation $\left(10,000 g_{\max }, 2 \mathrm{~min}\right)$. The aqueous phase was then transferred to an Eppendorf tube and the DNA was precipitated by addition of 0.54 volumes of propan-2-ol. The DNA was spooled on a pipettor tip and washed twice with $70 \%$ ethanol $(1 \mathrm{ml})$, dried in vacuo and resuspended in TE buffer containing $10 \mathrm{~mm}$ Tris/ $\mathrm{HCl}, \mathrm{pH} 8 \cdot 0,1 \mathrm{~mm}$ EDTA.

Preparation of probe DNA. $\lambda \mathrm{NS} 20$ and $\lambda \mathrm{NS} 21$ were selected at random from a library of $L$. pneumophila $E c o R 1$ fragments in the vector $\lambda g t W E S . \lambda B$ (Saunders $e t$ al., 1988a). DNA was purified from bacteriophage particles as described previously (Saunders et al., 1988b).

Labelling and hybridisation of probes. Purified DNA from $\lambda$ NS20 and $\lambda$ NS21 was labelled with biotin-11dUTP (Gibco) or [ $\alpha^{32}$ P]dCTP (Amersham) by primer extension. Southern blots were hybridised as described previously (Saunders et al., 1988b). After incubation, the filters were washed at low-stringency $2 \times$ SSC, SDS $0.1 \%$ at $50^{\circ} \mathrm{C}(2 \times 15 \mathrm{~min}$ and $1 \times 30 \mathrm{~min})$. The filters were airdried and developed with the Blu-gene ${ }^{\circledR}$ biotin detection reagents (Gibco) or subjected to autoradiography as appropriate.
Interpretation of the probed Southern blots. In most cases strains were subjected to analysis, and either assigned to a previously recorded RFLP type or to a new type, without prior reference to the relevant epidemiological data. The molecular size of restriction fragments observed in each pattern was estimated from a standard curve of relative mobility against molecular size of the $E c o \mathrm{R} 1$ and Pst 1 restriction fragments of $\lambda$ phage which were run in tracks adjacent to each sample. These data and visual examination were used for rapid comparison of the restriction fragment patterns observed so that strains could be assigned to the appropriate RFLP type.

\section{Evaluation of the RFLP-typing method}

The evaluation of the RFLP-typing method was based on three criteria: (A) the reproducibility of the technique; (B) the strain dependent stability of the RFLP type; and (C) the discrimination of the technique.

A. Reproducibility of technique. (i) DNA preparation. Twenty isolates were recovered from beads and cultured on two separate occasions. DNA was prepared from these strains by the two DNA extraction methods described above and the restriction fragment patterns obtained were compared.

(ii) The sequence dependent nature of the restriction fragment patterns. This was tested by subcloning the probe sequences into the polylinker of the plasmid vector pT7-1 (Boeringher Mannheim) adjacent to the T7 phage RNA polymerase promotor. RNA transcripts, produced in vitro with T7 RNA polymerase and biotinylated substrate biotin-11-UTP, were then used as probes and the banding patterns obtained were compared with those resulting from use of the primer extension labelled product.

(iii) Batch to batch variation of probe. Three batches of $\lambda$ NS20 and $\lambda$ NS21 DNA were prepared during the course of this study. Samples of these preparations were labelled and tested on fragments of $\lambda$ phage and on the strain NCTC 11286 (Knoxville-1).

(iv) Comparison of different probe labels. Probes were labelled either isotopically or non-isotopically as described above, and the results obtained were compared.

(v) Accuracy of RFLP type designation. Eleven isolates which had been designated RFLP type 1 during the course of the study were subsequently run on the same gel to determine if the restriction fragment patterns were indistinguishable even when compared on the same gel.

$B$. Strain dependent stability of restriction fragment patterns. Categories $\mathrm{i}-\mathrm{v}$ are summarised in table II.

(i) Multi-subcultured isolates. The Knoxville-1 strain and two further isolates (LC185 and LC190), chosen at random, were subcultured 90 times on BCYE. After every five subcultures growth was harvested and RFLPtyping performed.

(ii) Multiple isolates from a single clinical specimen. Thirteen isolates were obtained from single colonies taken from a primary isolation plate inoculated with a sputum specimen (LC308) from a patient with LD.

(iii) Isolates obtained by different techniques from the 
Table I. Summary of the 100 unrelated isolates used in the estimation of discrimination

\begin{tabular}{|c|c|c|c|c|c|c|c|}
\hline Strain no. & Source & $\begin{array}{c}\text { RFLP type } \\
\text { (number of isolates) }\end{array}$ & $\begin{array}{c}\text { MAb } \\
\text { subgroup* }\end{array}$ & Strain no. & Source & $\begin{array}{c}\text { RFLP type } \\
\text { (number of isolates) }\end{array}$ & $\begin{array}{c}\text { MAb } \\
\text { subgroup* }\end{array}$ \\
\hline ML56 & $C(\mathbf{U K})$ & $1(26)$ & Philadelphia & A32/81 & E (UK) & $11(1)$ & Knoxville \\
\hline ML93 & $\mathrm{C}(\mathrm{Eu})$ & 1 & Philadelphia & & E(Aus) & $12(1)$ & Bellingham \\
\hline ML124 & $\mathrm{C}$ (UK) & 1 & Philadelphia & Al00/81 & E (Aus) & & \\
\hline ML133 & $\mathrm{C}(\mathrm{Ch})$ & 1 & Philadelphia & LC19 & $\mathrm{C}(\mathrm{Fr})$ & $13(2)$ & Bellingham \\
\hline $\mathrm{LC} 26$ & $\mathrm{C}(\mathrm{Fr})$ & 1 & Philadelphia & LC51 & $\mathrm{C}(\mathrm{Fr})$ & 13 & Bellingham \\
\hline LC32 & $\mathrm{C}$ (Fr) & 1 & Philadelphia & ML199 & $\mathrm{C}(\mathrm{I})$ & $14(5)$ & Benidorm \\
\hline $\begin{array}{l}\text { LC81 } \\
\text { LC433 }\end{array}$ & C(UK) & 1 & Philadelphia & $\begin{array}{l}\text { ML199 } \\
\text { LC80 }\end{array}$ & $\mathrm{C}(\mathrm{Sp})$ & 14 & Benidorm \\
\hline LC433 & C (UK) & 1 & Philadelphia & LC230 & $\mathrm{C}(\mathrm{Eu})$ & 14 & Benidorm \\
\hline LC631 & $\mathrm{E}(\mathrm{UK})$ & 1 & Philadelphia & Al67/80 & $\mathrm{C}(\mathrm{Eu})$ & 14 & Benidorm \\
\hline $\begin{array}{l}\text { LC41 } \\
\text { LRU16 }\end{array}$ & $\begin{array}{l}C(F r) \\
E(U K)\end{array}$ & $\begin{array}{l}1 \\
1\end{array}$ & $\begin{array}{l}\text { Allentown } \\
\text { Allentown }\end{array}$ & LC412 & $\mathrm{C}(\mathrm{Gr})$ & 14 & Benidorm \\
\hline LC28 & $\mathrm{C}(\mathrm{Fr})$ & 1 & Benidorm & A218/80 & E (UK) & & \\
\hline A $310 / 80$ & $\mathrm{C}$ (UK) & 1 & Benidorm & $\pi 210 / 00$ & L(UN) & $15(1)$ & Bellıngham \\
\hline LC20 & $\mathrm{E}(\mathrm{Fr})$ & 1 & France & A176/79 & $\mathrm{C}$ (USA) & $16(1)$ & Philadelphia \\
\hline LC620 & C (UK) & 1 & France & LC22 & $\mathrm{C}(\mathrm{Fr})$ & $17(1)$ & Bellingham \\
\hline $\begin{array}{l}\text { LC629 } \\
\text { LC54 }\end{array}$ & $\begin{array}{l}\mathrm{E}(\mathrm{UK}) \\
\mathrm{C}(\mathrm{Fr})\end{array}$ & 1 & $\begin{array}{l}\text { Olda } \\
\text { Oxford }\end{array}$ & LC435 & $\mathrm{C}(\mathrm{Gr})$ & $18(1)$ & Philadelphia \\
\hline LC400 & $\mathrm{E}(\mathbf{U K})$ & 1 & Oxford & & & & \\
\hline LC470 & E (UK) & 1 & Oxford & $\begin{array}{l}\text { LC372 } \\
\text { LC642 }\end{array}$ & $\begin{array}{l}\mathrm{C} \text { (UK) } \\
\mathrm{E} \text { (UK) }\end{array}$ & $\begin{array}{l}19(2) \\
19\end{array}$ & $\begin{array}{l}\text { Benidorm } \\
\text { Benidorm }\end{array}$ \\
\hline $\begin{array}{l}\text { LC6 } \\
\text { LC260 }\end{array}$ & C (UK) & 1 & Heysham & & & & \\
\hline $\begin{array}{l}\text { LC260 } \\
\text { LC636 }\end{array}$ & $\begin{array}{l}\mathrm{C}(\mathrm{UK}) \\
\mathrm{E}(\mathrm{UK})\end{array}$ & 1 & Heysham & ML47 & C (UK) & $20(1)$ & Benidorm \\
\hline A $29 / 81$ & E (UK) & 1 & Heysham & LC36 & $\mathrm{C}(\mathrm{Fr})$ & $21(1)$ & France \\
\hline LRU7 & $\mathrm{E}(\mathrm{UK})$ & 1 & Camperdown & LC22 & $\mathrm{C}(\mathrm{Fr})$ & $22(1)$ & Bellingham \\
\hline $\begin{array}{l}\text { LC359 } \\
\text { LC521 }\end{array}$ & ?(USA) & 1 & Other & LC457 & E (Sing) & $23(2)$ & Philadelphia \\
\hline LC521 & E (UK) & 1 & Other & ML72 & $\mathrm{C}(\mathrm{I})$ & 23 & Benidorm \\
\hline $\begin{array}{l}\text { LC376 } \\
\text { NCTC } 11191\end{array}$ & $\begin{array}{l}\text { C (UK) } \\
\text { E (USA) }\end{array}$ & $\begin{array}{l}2(2) \\
2\end{array}$ & $\begin{array}{l}\text { Philadelphia } \\
\text { Philadelphia }\end{array}$ & LC436 & $\mathrm{C}(\mathrm{Yu})$ & $24(1)$ & Allentown \\
\hline (Pontiac-1) & & & & ML60 & $\mathrm{C}(\mathrm{UK})$ & $25(3)$ & Knoxville \\
\hline ML51 & C (Czech) & $3(3)$ & Knoxville & LC421 & $\mathrm{C}$ (UK) & 25 & Knoxville \\
\hline NCTC 11286 & $\mathrm{C}($ USA) & 3 & Knoxville & LC669 & $\mathrm{C}(\mathrm{UK})$ & 25 & Knoxville \\
\hline $\begin{array}{l}\text { (Knoxville-1) } \\
\text { LC647 }\end{array}$ & E (UK) & 3 & Bellingham & ML54 & $\mathrm{C}(\mathrm{UK})$ & $26(8)$ & Philadelphia \\
\hline & & (2) & bemmgnam & LC185 & $\mathrm{C}(\mathrm{Fr})$ & 26 & Philadelphia \\
\hline $\begin{array}{l}\text { LC358 } \\
\text { NCTC } 11404\end{array}$ & E (Sing) & $4(2)$ & Bellingham & LC460 & $\mathrm{C}(\mathrm{Fr})$ & $\begin{array}{l}26 \\
26\end{array}$ & $\begin{array}{l}\text { Philadelphia } \\
\text { France }\end{array}$ \\
\hline $\begin{array}{l}\text { NCTC } 11404 \\
\text { (Bellingham-1) }\end{array}$ & C (USA) & 4 & Bellingham & $\begin{array}{l}\text { LC190 } \\
\text { LC199 }\end{array}$ & $\begin{array}{l}C(\mathrm{Fr}) \\
\mathrm{C}(\mathrm{Fr})\end{array}$ & $\begin{array}{l}20 \\
26\end{array}$ & $\begin{array}{l}\text { France } \\
\text { France }\end{array}$ \\
\hline (Bellingham-1) & & & & LC62 & $\mathrm{C}(\mathrm{N})$ & 26 & Knoxville \\
\hline LC423 & $\mathrm{C}$ (UK) & $5(12)$ & Philadelphia & LC661 & E (UK) & 26 & Bellingham \\
\hline LC480 & E (UK) & 5 & Philadelphia & A358/80 & $\mathrm{C}(\mathrm{Fr})$ & 26 & Philadelphia \\
\hline LC536 & C (UK) & 5 & Philadelphia & & $\mathrm{C}(\mathrm{UK})$ & & Oxford \\
\hline LC639 & C (UK) & 5 & Philadelphia & LC547 & E (UK) & 27 & Olda \\
\hline LC660 & C (UK) & 5 & Philadelphia & LC567 & $\mathrm{E}(\mathrm{UK})$ & 27 & Olda \\
\hline LRU78 & C(UK) & $\begin{array}{l}5 \\
5\end{array}$ & $\begin{array}{l}\text { Philadelphia } \\
\text { Philadelphia }\end{array}$ & LC514 & E (Sing) & 27 & Oxford \\
\hline $\begin{array}{l}\text { NCTC } 11192 \\
\text { (Philadelphia-1) }\end{array}$ & $\mathrm{C}$ (USA) & 5 & Philadelphia & & & & \\
\hline $\begin{array}{l}\text { LC512 } \\
\text { LC99 }\end{array}$ & C (UK) & $\begin{array}{l}5 \\
5\end{array}$ & Philadelphia & $\begin{array}{l}\text { MLO8 } \\
\text { ML150 }\end{array}$ & $\mathrm{C}(\mathrm{N})$ & $\begin{array}{l}28(2) \\
28\end{array}$ & $\begin{array}{l}\text { Philadelphia } \\
\text { Benidorm }\end{array}$ \\
\hline $\begin{array}{l}\text { LC99 } \\
\text { LC31 }\end{array}$ & $\begin{array}{l}\mathrm{C}(\mathrm{Fr}) \\
\mathrm{C}(\mathrm{Fr})\end{array}$ & $\begin{array}{l}5 \\
5\end{array}$ & $\begin{array}{l}\text { Allentown } \\
\text { France }\end{array}$ & LC564 & $\mathrm{E}$ (Ost) & $29(1)$ & Allentown \\
\hline LC57 & $\begin{array}{l}\mathrm{C}(\mathrm{Fr}) \\
\mathrm{C}(\mathrm{Fr})\end{array}$ & 5 & France & & & $31(1)$ & \\
\hline LC173 & $\mathrm{C}(\mathrm{Fr})$ & 5 & France & ML8I & $E(\mathbf{H K})$ & $31(1)$ & Olda \\
\hline LC360 & ?(USA) & $6(1)$ & Other & ML607 & $\mathrm{E}(\mathrm{UK})$ & $32(1)$ & Other \\
\hline LC409 & $\mathrm{E}(\mathrm{UK})$ & $7(3)$ & Allentown & LC657 & $E(T k)$ & $35(1)$ & Olda \\
\hline LC474 & E (UK) & 7 & Allentown & LC635 & $\mathrm{C}(\mathrm{Yu})$ & $36(1)$ & Benidorm \\
\hline LRUS & $\mathrm{E}(\mathrm{UK})$ & 7 & Oxford & LC638 & $\mathrm{E}(\mathrm{UK})$ & $37(1)$ & Bellingham \\
\hline LC235 & $\mathrm{C}(\mathrm{Po})$ & $8(1)$ & Allentown & LC667 & $\mathrm{C}$ (Dom) & $38(1)$ & Benidorm \\
\hline $\begin{array}{l}\text { ML70 } \\
\text { LRU89 }\end{array}$ & $\begin{array}{l}C(\text { UK }) \\
C(U K)\end{array}$ & $\begin{array}{l}10(3) \\
10\end{array}$ & $\begin{array}{l}\text { Benidorm } \\
\text { Benidorm }\end{array}$ & LC518 & $\mathrm{E}(\mathrm{UK})$ & $39(1)$ & Bellingham \\
\hline LC380 & $\mathrm{E}(\mathrm{UK})$ & 10 & Bellingham & LC615 & $\mathrm{C}(\mathrm{Gr})$ & Untypable (1) & Allentown \\
\hline
\end{tabular}

$\mathrm{C}=$ clinical isolate $\mathrm{E}=$ environmental isolate $;=$ source not known. The country of origin (environmental isolates) or country in which a patient was thought to have contracted their illness (clinical isolate) is indicated as follows: UK = United Kingdom; Eu=continental Europe (more than one country visited during the incubation period); $\mathrm{Ch}=$ Switzerland; $\mathrm{Fr}=$ France; USA = United States of America; Czech $=\mathrm{Czechoslovakia;}$ Sing $=$ Singapore $; \mathrm{Po}=$ Portugal $;$ Aus $=$ Australia $; \mathrm{I}=\mathrm{Italy} ; \mathrm{Sp}=$ Spain $; \mathrm{Gr}=$ Greece $; \mathrm{Yu}=$ Yugoslavia $; \mathrm{N}=$ Netherlands $;$ Ost $=\mathrm{Austria} ; \mathrm{HK}=\mathrm{Hong}$ Kong; Tk = Turkey; Dom = Dominican Republic.

"MAb subgroup as designated by Joly et al. (1986) except "Other" which indicates that the pattern of reaction did not fit into the described scheme. 
Table II. Summary of the strains examined in the assessment of reproducibility

\begin{tabular}{|c|c|c|c|c|c|}
\hline Strain no. & Source* & & Category $†$ & $\begin{array}{c}\text { RFLP } \\
\text { type }\end{array}$ & $\begin{array}{c}\text { MAb } \\
\text { subgroup }\end{array}$ \\
\hline Knoxville-1 & $\mathrm{C}$ (USA) & $\mathrm{Bi}$ & Multiple passage & 3 & Knoxville \\
\hline LC185 & $\mathrm{C}(\mathrm{Fr})$ & & Multiple passage & 26 & Philadelphia \\
\hline $\mathrm{LC} 190$ & $\mathrm{C}(\mathrm{Fr})$ & & Multiple passage & 26 & France \\
\hline LC308 & $\mathrm{C}(\mathrm{UK})$ & $\mathrm{Bii}$ & $\begin{array}{l}\text { Multiple colonies (13) from } \\
\text { single specimen }\end{array}$ & 1 & Heysham \\
\hline LC230\} & $\mathrm{C}(\mathrm{Sp})$ & Biii & Direct plating of sputum & 14 & Benidorm \\
\hline LC231\} & & & Amoebal enrichment & 14 & Benidorm \\
\hline LC462 & $\mathrm{C}(\mathrm{Sp})$ & & Direct plating of sputum & 14 & Benidorm \\
\hline LC463 & & & Amoebal enrichment & 14 & Benidorm \\
\hline LC260 & $\mathrm{C}(\mathrm{UK})$ & Biv & Lung washings $(7 / 5)$ & 1 & Heysham \\
\hline LC308 & & & Sputum $(12 / 5)$ & 1 & Heysham \\
\hline LC372 & $\mathrm{C}(\mathrm{UK})$ & & Sputum $(13 / 6)$ & 19 & Benidorm \\
\hline LC373 & & & Sputum $(15 / 6)$ & 19 & Benidorm \\
\hline LC669 & $\mathrm{C}(\mathrm{UK})$ & & Sputum & 25 & Knoxville \\
\hline LC676 & & & Post-mortem lung & 25 & Knoxville \\
\hline ML60 & & Bv & Clinical isolates from Stafford & 25 & Knoxville \\
\hline ML61 & & & District Hospital outbreak $\ddagger$ & 25 & Knoxville \\
\hline ML62 & & & & 25 & Knoxville \\
\hline ML63 & $\mathrm{C}(\mathrm{UK})$ & & & 25 & Knoxville \\
\hline ML64 & & & & 25 & Knoxville \\
\hline ML65 & & & & 25 & Knoxville \\
\hline ML66 & & & & 25 & Knoxville \\
\hline LC436 & $\mathrm{C}(\mathrm{Yu})$ & & Clinical isolates from Yugo- & 24 & Allentown \\
\hline LRU88 & & & slavian hotel outbreak§ & 24 & Allentown \\
\hline LC62 & $C(N)$ & & Clinical and environmental & 26 & Knoxville \\
\hline LC63 & $E(N)$ & & isolates from Dutch Hospital & 26 & Knoxville \\
\hline LC65 & $\mathrm{E}(\mathrm{N})$ & & outbreak & 26 & Knoxville \\
\hline LC66 & $\mathrm{E}(\mathrm{N})$ & & & 26 & Knoxville \\
\hline LC67 & $\mathrm{C}(\mathrm{N})$ & & & 26 & Knoxville \\
\hline LC68 & $E(N)$ & & & 26 & Knoxville \\
\hline LC69 & $\mathrm{C}(\mathrm{N})$ & & & 26 & Knoxville \\
\hline LC70 & $\mathrm{E}(\mathrm{N})$ & & & 26 & Knoxville \\
\hline LC71 & $\mathrm{C}(\mathrm{N})$ & & & 26 & Knoxville \\
\hline LC536 & & & Clinical isolates from Port- & 5 & Philadelphia \\
\hline LC537 & & & land Place outbreak & 5 & Philadelphia \\
\hline LC539 & & & & 5 & Philadelphia \\
\hline LC540 & & & & 5 & Philadelphia \\
\hline LC541 & $\mathrm{C}$ (UK) & & & 5 & Philadelphia \\
\hline LC568 & & & & 5 & Philadelphia \\
\hline LC583 & & & & 5 & Philadelphia \\
\hline LC584 & & & & 5 & Philadelphia \\
\hline LC660 & C (UK) & & Clinical isolate from Lostock & 5 & Philadelphia \\
\hline LC671 & & & outbreak** & 5 & Philadelphia \\
\hline
\end{tabular}

\footnotetext{
* See footnote to table I.

$\dagger$ Category-The category, as defined in Materials and Methods section B., in the study of reproducibility for which the strains were used.

$\ddagger$ Badenoch (1986).

$\S$ Communicable Disease Surveillance Centre (1987). Confidential report.

$\|$ van Ketel et al. (1984).

T City of Westminster (1988).

** Communicable Disease Surveillance Centre (1988). Confidential report.
}

same clinical specimen. Isolates were obtained from two patients from a single specimen by both direct plating and by amoebal enrichment (Rowbotham, 1983).

(iv) Isolates from different clinical specimens from the same patient. Two isolates, each from a different clinical specimen were examined from each of three patients. (v) Isolates from epidemiologically associated patients. Isolates were available from 23 patients associated with five outbreaks of LD.

C. Discrimination. The discrimination of the method was determined by considering the number and frequency of different restriction fragment patterns obtained when 
100 apparently unrelated isolates were examined. The numerical index of discrimination was calculated as described by Hunter and Gaston (1988).

\section{Monoclonal antibody (MAb) subgrouping}

MAb subgrouping was performed as described by Joly et al. (1986) with reagents kindly supplied by Drs R. McKinney, J. Joly and J. Tobin.

\section{Plasmid analysis}

Plasmid DNA was isolated by the method of Kado and Liu (1981), subjected to electrophoresis in agarose $0.7 \%$ gels cast in Tris/borate buffer $(89 \mathrm{~mm}$ Tris, $89 \mathrm{mM}$ borate, $2 \mathrm{mM}$ EDTA) at $10 \mathrm{~V} / \mathrm{cm}$ for $2 \mathrm{~h}$ and stained with ethidium bromide. The reservoir buffer employed for these studies was Tris/acetate $(40 \mathrm{~mm}$ Tris/acetate, $\mathrm{pH}$ 8.0, 1 mM EDTA). Escherichia coli strain 39R861 (NCTC 50192 ), which bears plasmids of $98,42,23.9$ and $4.6 \mathrm{Mdal}$ was analysed concurrently to provide molecular weight standards.

\section{Results}

\section{A. Reproducibility}

The characteristic patterns of bands observed for individual strains were found to be independent of the following variables: (1) the method of DNA preparation (batches of DNA prepared from strains by the two methods); (2) the batch of $\lambda$ NS20 and $\lambda$ NS21 DNA used; (3) probe comprised of RNA or DNA (the probes derived by primer extension on the $\lambda$ templates were compared with RNA transcript probes synthesised with the same sequences cloned into the plasmid pT7-1); (4) the label and detection system (labelling of probe DNA or RNA with radioactive or biotinylated nucleotides followed by autoradiographic or enzymatic detection).

The reliability of RFLP type designation is demonstrated in fig. 1 , which shows strains identified as type 1 by examination of different typing gels subsequently run in adjacent tracks of the same gel.

One variable that did not give rise to reproducible results was the batch of agarose employed. Some lots were incompatible with efficient transfer of DNA from the gel to the solid support. Furthermore, it was noted that in some instances the transfer of the larger DNA fragments was most seriously affected. Problems of this kind are easily identified because the $\lambda$ standards are also affected and thus strains are not wrongly typed. The

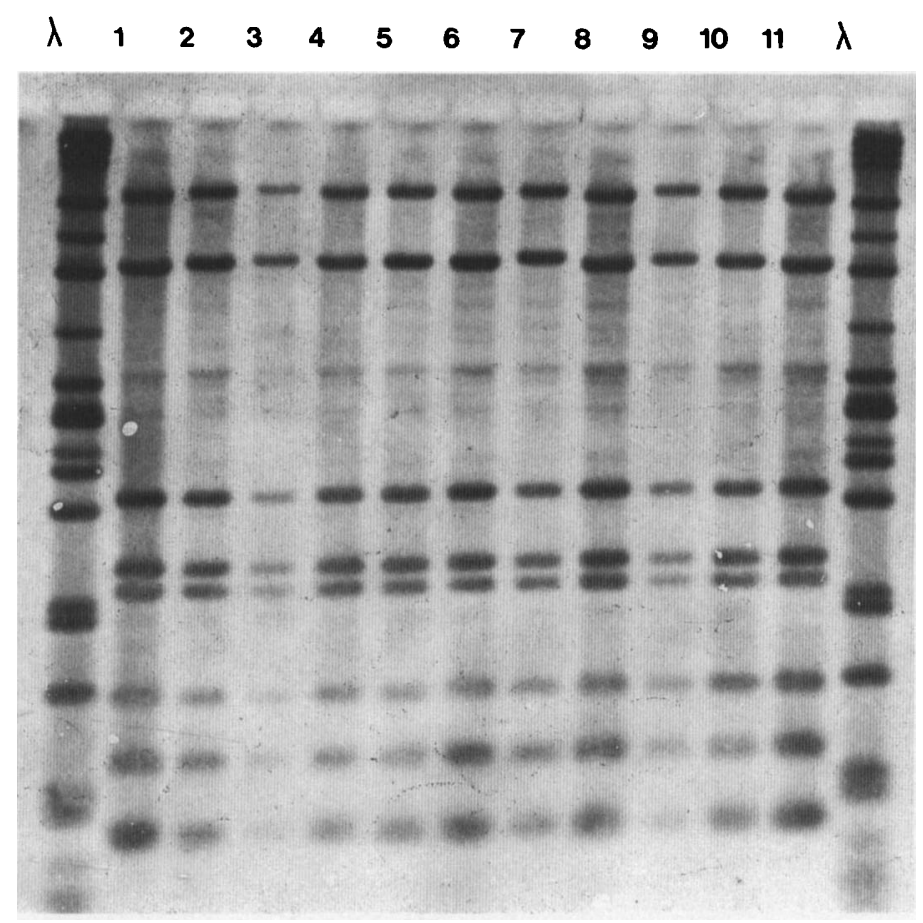

of $E c o$ RI and PstI digests of $\lambda$ phage DNA. Numbered tracks

track) were subjected to electrophoresis at $1.25 \mathrm{~V} / \mathrm{cm}$ for $16 \mathrm{~h}$. The DNA was blotted and hybridised to biotinylated probe (300 ng). Bound probe was visualised by the Blu-gene reagents. Tracks marked $\lambda$ show a mixture of EcoR1 and Pst 1 digests of $\lambda$ phage DNA. follows: 1,$1 ; 2,5 ; 3,10 ; 4,15 ; 5,20 ; 6,25 ; 7,30 ; 8,35 ; 9,40$; 
reproducibility of DNA transfer from gels cast with the same batch of agarose was excellent. No problems were encountered with several batches of 'Ultra Pure' agarose (BRL Ltd).

\section{B. Stability}

Fig. 2 shows the patterns obtained from the Knoxville-1 strain after serial subcultivation ( $\mathrm{Ma}$ terials and methods, $\mathrm{Bi}$ ). No differences were observed between the patterns indicating that the relevant part of the genome was stable under laboratory conditions of cultivation. The two other strains, LC185 and LC190, which were also subjected to serial subcultivation showed no pattern variation (results not shown).

The results of the RFLP analysis of the isolates described in $\mathrm{B}$ ii-iv demonstrated that the RFLP patterns were stable. Within each category of relationship, the isolates examined gave indistinguishable patterns (table II).

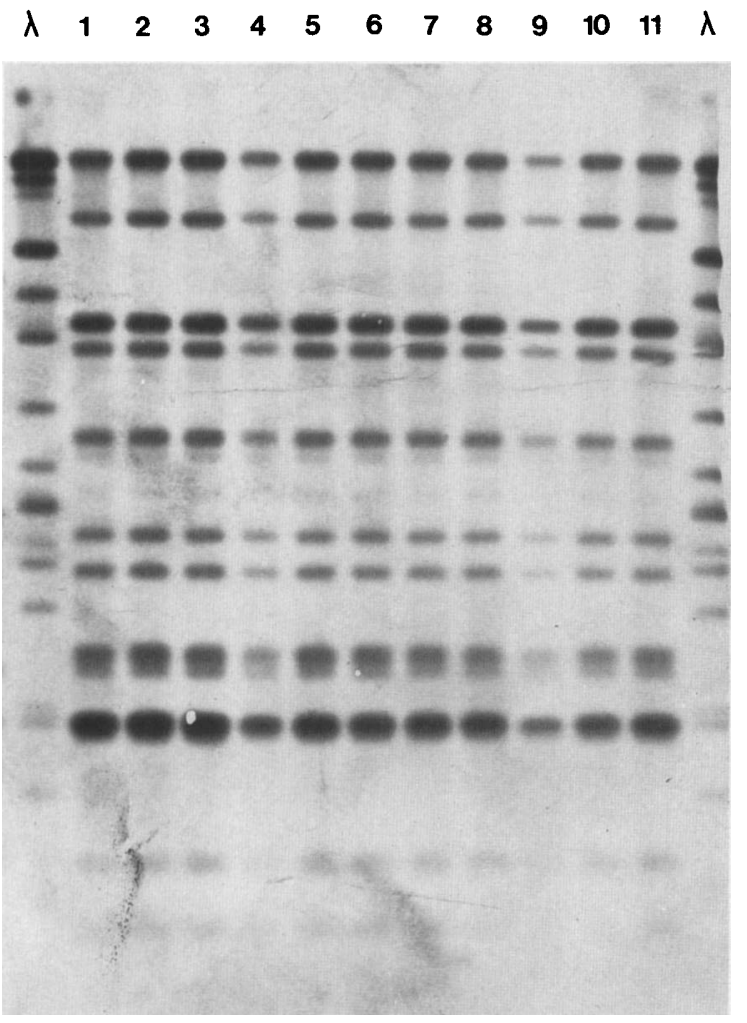

Fig. 2. Ncil restriction fragments from the Knoxville-1 strain after up to 90 subcultivations. The gel was run and treated as described in the legend to fig. 1. Tracks marked $\lambda$ show a mixture of $E c o \mathrm{R} 1$ and $P s t \mathrm{I}$ digests of $\lambda$ phage DNA. Numbered tracks (1-11) show the patterns obtained for the Knoxville-1 strain (NCTC11286) after up to 90 subcultivations on BCYE as follows: 1,$1 ; 2,5 ; 3,10 ; 4,15 ; 5,20 ; 6,25 ; 7,30 ; 8,35 ; 9,40$; 10,$45 ; 11,90$. (v) Typing of epidemiologically related isolates. Fig. 3 shows the restriction fragment patterns obtained with two of the five sets of epidemiologically related strains examined in this study (table II, Bv). Tracks 5-11 show seven strains isolated from different patients infected in the outbreak of LD at Stafford District General Hospital in 1985; all of the isolates gave indistinguishable patterns (RFLP type 25). This supports the epidemiological evidence that all of the cases were caused by dispersal of legionellae from a single source-a contaminated cooling tower at the hospital (Badenoch, 1986). Tracks 1 and 2 show the patterns of bands (RFLP type 24) obtained by analysis of clinical isolates from two further cases of LD. In this instance both the patients, one of whom was resident in Holland and the other in England, had stayed in the same Yugoslavian hotel at the time of an outbreak of LD (Communicable Disease Surveillance Centre, 1987). This RFLP type has not been observed in any of the other isolates examined to date.

The nine isolates from an outbreak of LD at a Dutch hospital (van Ketel et al., 1984) also gave indistinguishable patterns of bands (RFLP type 26). Four of these strains were clinical isolates and five were cultured from the water supplies to their respective hospital wards.

Finally, the eight clinical isolates from patients in the outbreak of LD at the British Broadcasting Corporation, Portland Place, London, all gave the same RFLP type (type 5) as did the two clinical isolates from the cases of LD at Lostock, Bolton (Communicable Disease Surveillance Centre, 1988).

\section{Discrimination between strains}

Examination of the 100 unrelated L. pneumophila serogroup 1 strains (table I) revealed 34 distinct patterns of restriction fragments hybridising to the probe. The patterns of 23 strains of different RFLP type are shown in fig. 4 . The DNA from a single strain (LC615) was refractory to digestion with $\mathrm{Ncil}$ and was, therefore, untypable. The distribution of strains into RFLP types was not uniform with some pattern types being. shared by many isolates (table I and III). The numerical index of discrimination (the probability of two unrelated strains being of different RFLP types) of the RFLP typing method calculated from these data is 0.9095 .

Typing of Heysham-1 and LC628 strains which were of the 'related' group according to the criteria applied, revealed two further RFLP types (30 and 33 respectively). These were not included in the 


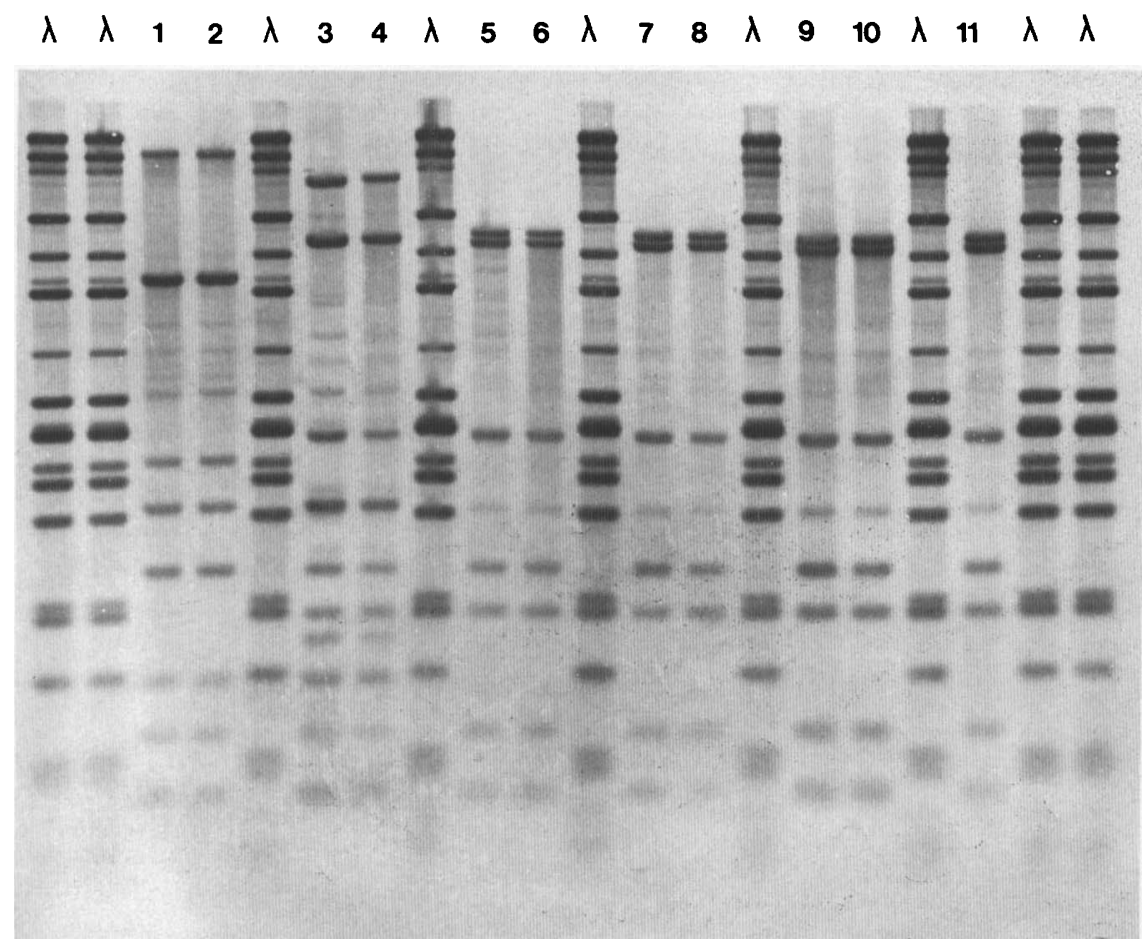

Fig. 3. Ncil restriction fragments from L. pneumophila strains detected with the probes $\lambda 20$ and $\lambda 21$. The gel was run and treated as described in the legend to fig. 1. Tracks marked $\lambda$ show a mixture of $E c o R 1$ and Pst 1 digests of $\lambda$ phage DNA. Numbered tracks ML63; 9, ML64; 10, ML65; 11, ML66.

estimation of discrimination. All of the other isolates in the 'related' group were of one of the 34 pattern types observed for the 100 'unrelated' strains.

\section{Influence of plasmid content on RFLP typing}

To determine whether or not plasmid DNA would modify the RFLP type of an isolate, the plasmid content of the 100 unrelated strains was examined. Plasmids of approximate size 104, 98, $81,70,53,45,32$ and 30 Mda were identified in 35 strains. Three strains contained more than one plasmid. None of these plasmids hybridised to sequences of $\lambda N S 20$ or $\lambda N S 21$. Furthermore, it was also noted that both plasmid-bearing and plasmidfree strains were present in the same RFLP type in the case of 9 of the 15 RFLP types which contained more than one isolate. All three isolates of RFLP type 7 contained plasmids but these were of different sizes.

\section{Comparison of RFLP typing with MAb subgrouping}

The MAb subgroups of the 100 unrelated strains are shown in table I and their distribution with respect to RFLP type in table III. The pattern of $M A b$ reactions of four isolates did not fit into any of the 10 established subgroups. The results from epidemiologically associated strains were consistent with the results of RFLP typing.

There was no clear correlation between MAb subgroup and RFLP type except that the five strains of RFLP type 14 were all found to be of the 'Benidorm' subgroup. In most instances, the discrimination achieved by RFLP typing could be increased by subdivision of the types into $\mathrm{MAb}$ subgroups. For example, the 26 strains of RFLP type 1 fall into nine $\mathrm{MAb}$ subgroups (including 'Other'). Conversely the RFLP typing method splits all of the MAb subgroups except 'Heysham' and 'Camperdown' of which only four and one representative strains, respectively, were available for analysis. These were all of RFLP type 1.

\section{Discussion}

We have used restriction fragments derived from a small proportion of the $L$. pneumophila genome as markers to distinguish between strains. The method is based on the detection of minor differences in 


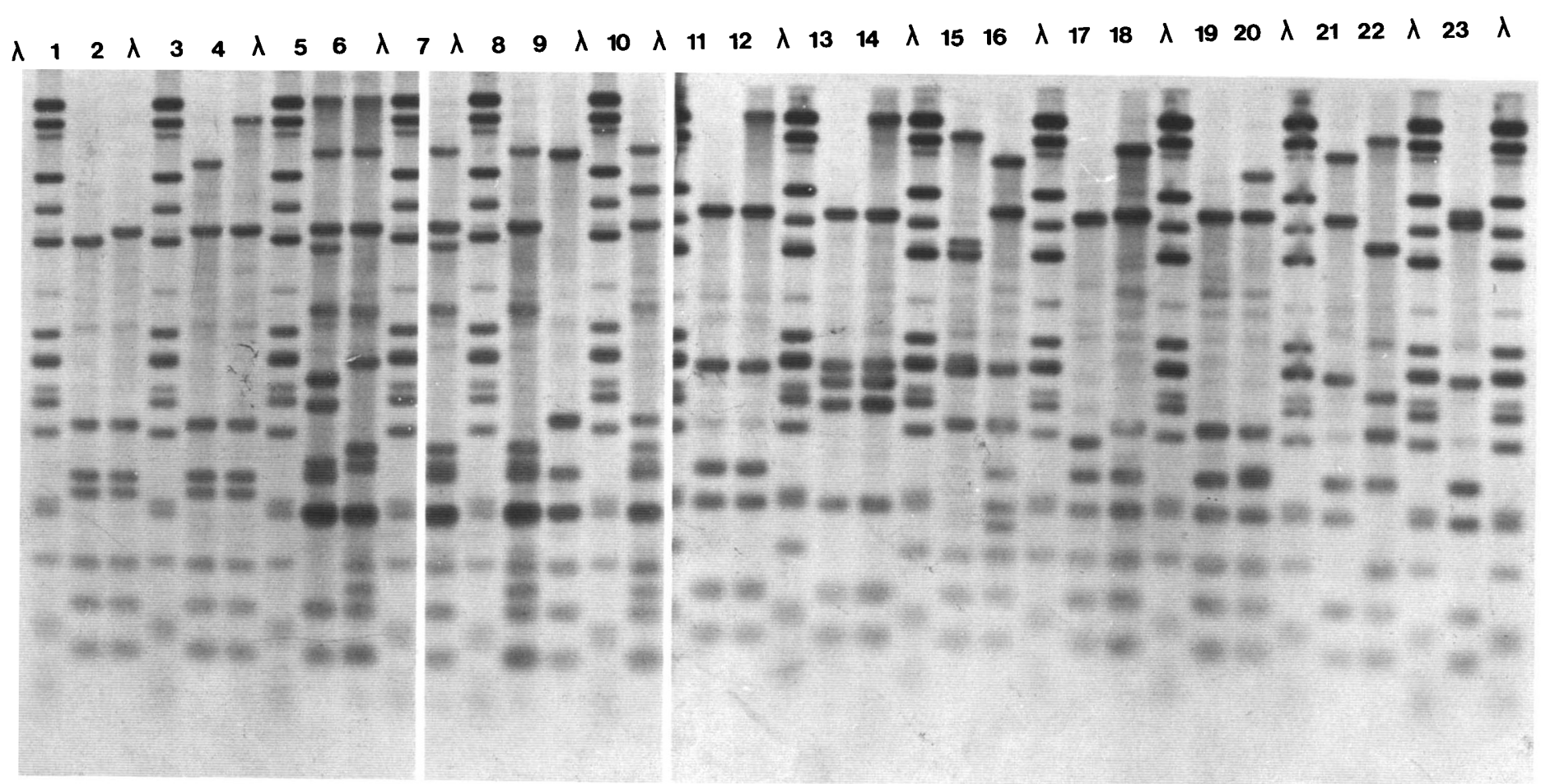

Fig. 4. Distinct $N c i 1$ restriction fragment patterns of 23 strains detected with the probes $\lambda 20$ and $\lambda 21$. The gel was run and treated as described in the legend to fig 1 . Tracks marked $\lambda$ show a mixture of $E c o R 1$ and $P$ st l digests of $\lambda$ phage DNA. Numbered tracks show the pattern types obtained for 23 strains as follows: 1. LC409 type 7; A175/79, type 27;3, LC54, type 1;4, LC457, type 23;5, Knoxville-1, type 3;6, Bellingham-1, type 4; 7, A100/81, type 12;8, LC51, type 13; 1, LC C99, type 7, 2, A 10 9. A176/79, type 16; 10, LC22, type 17; 11, Philadelphia-1, type 5; 1, LC 15; 20, LC36, type 21; 21, LC27, type 22; 22, LC436, type 24; 23 , LC421, type 25. 
Table III. Relationship between RFLP type and MAb subgroup for the 100 unrelated strains

\begin{tabular}{|c|c|c|c|c|c|c|c|c|c|c|c|c|}
\hline \multirow{2}{*}{$\begin{array}{c}\text { RFLP } \\
\text { type }\end{array}$} & \multicolumn{11}{|c|}{ Number of strains $(\mathrm{c} / \mathrm{e})^{*}$ of MAb subgroup $\dagger$} & \multirow[b]{2}{*}{ Totals } \\
\hline & Phil & Knox & Beni & Alle & Fran & OLDA & Oxfo & Heys & Camp & Bell & Other & \\
\hline 1 & $8 / 1$ & & $2 / 0$ & $1 / 1$ & $1 / 1$ & $0 / 1$ & $1 / 2$ & $2 / 2$ & $0 / 1$ & & $0 / 2$ & $15 / 11$ \\
\hline 2 & $1 / 1$ & & & & & & & & & & & $1 / 1$ \\
\hline 3 & & $2 / 0$ & & & & & & & & $0 / 1$ & & $2 / 1$ \\
\hline 4 & & & & & & & & & & $1 / 1$ & & $1 / 1$ \\
\hline 5 & $7 / 1$ & & & $1 / 0$ & $3 / 0$ & & & & & & & $11 / 17$ \\
\hline 6 & & & & & & & & & & & $0 / 1$ & $0 / 1$ \\
\hline 7 & & & & $0 / 2$ & & & $0 / 1$ & & & & & $0 / 3$ \\
\hline 8 & & & & $1 / 0$ & & & & & & & & $1 / 0$ \\
\hline 10 & & & $2 / 0$ & & & & & & & $0 / 1$ & & $2 / 1$ \\
\hline 11 & & $0 / 1$ & & & & & & & & & & $0 / 1$ \\
\hline 12 & & & & & & & & & & $0 / 1$ & & $0 / 1$ \\
\hline 13 & & & & & & & & & & $2 / 0$ & & $2 / 0$ \\
\hline 14 & & & $5 / 0$ & & & & & & & & & $5 / 0$ \\
\hline 15 & & & & & & & & & & $0 / 1$ & & $0 / 1$ \\
\hline 16 & $1 / 0$ & & & & & & & & & & & $1 / 0$ \\
\hline 17 & & & & & & & & & & $1 / 0$ & & $1 / 0$ \\
\hline 18 & $1 / 0$ & & & & & & & & & & & $1 / 0$ \\
\hline 19 & & & $1 / 1$ & & & & & & & & & $1 / 1$ \\
\hline 20 & & & $1 / 0$ & & & & & & & & & $1 / 0$ \\
\hline 21 & & & & & & & & & & $1 / 0$ & & $1 / 0$ \\
\hline 22 & & & & & $1 / 0$ & & & & & & & $1 / 0$ \\
\hline 23 & $0 / 1$ & & $1 / 0$ & & & & & & & & & $1 / 1$ \\
\hline 24 & & & & $1 / 0$ & & & & & & & & $1 / 0$ \\
\hline 25 & & $3 / 0$ & & & & & & & & & & $3 / 0$ \\
\hline 26 & $3 / 0$ & $1 / 0$ & & & $2 / 0$ & & & & & $0 / 2$ & & $6 / 2$ \\
\hline 27 & & & $1 / 0$ & & & $0 / 2$ & $0 / 1$ & & & & & $1 / 3$ \\
\hline 28 & $1 / 0$ & & $1 / 0$ & & & & & & & & & $2 / 0$ \\
\hline 29 & & & & $0 / 1$ & & & & & & & & $0 / 1$ \\
\hline 31 & & & & & & $0 / 1$ & & & & & & $0 / 1$ \\
\hline 32 & & & & & & & & & & & $0 / 1$ & $0 / 1$ \\
\hline 35 & & & & & & $0 / 1$ & & & & & & $0 / 1$ \\
\hline 36 & & & $1 / 0$ & & & & & & & & & $1 / 0$ \\
\hline 37 & & & & & & & & & & $0 / 1$ & & $0 / 1$ \\
\hline 38 & & & $1 / 0$ & & & & & & & & & $1 / 0$ \\
\hline 39 & & & & & & & & & & $0 / 1$ & & $0 / 1$ \\
\hline Unty & & & & $1 / 0$ & & & & & & & & $1 / 0$ \\
\hline Total & $22 / 4$ & $6 / 1$ & $16 / 1$ & $5 / 4$ & $7 / 1$ & $0 / 5$ & $1 / 4$ & $2 / 2$ & $0 / 1$ & $5 / 9$ & $0 / 4$ & $64 / 36$ \\
\hline
\end{tabular}

* $\mathrm{c}=$ Clinical strains; $\mathrm{e}=$ environmental strains.

$\dagger$ See table II for full names of MAb subgroups.

base sequence which often cannot be discerned in the phenotype. The probe size and restriction enzyme was selected so that patterns of about 7-10 bands were generated from L. pneumophila strains.

The two cloned sequences employed as probes in this study were selected from a bacteriophage $\lambda$ genomic library of $L$. pneumophila Knoxville-1 (NCTC 11286) DNA. Both probe sequences appear to have broad specificity, being able to hybridise with restriction fragments from all L. pneumophila strains examined so far irrespective of serogroup (unpublished results). The two sequences hybridise with $L$. pneumophila DNA restriction fragments to give different patterns showing them to be effec- tively independent. When the test strain DNA was digested with the restriction enzyme Ncil the patterns generated by the two sequences tended not to interfere as their associated bands occupied different regions of the Southern blot. We have found that $N c i 1$, which cuts target DNA at the sequence $5^{\prime}-\mathrm{CC}_{\mathrm{C}}^{\mathrm{G}} \mathrm{GG}-3^{\prime}$, generates sufficient fragments complementary to the probe to provide useful results.

The results of this study demonstrate that, as may be expected, the pattern of bands observed for each strain depends only upon the source of the chromosomal DNA, the sequence of the probe employed and the specificity of the restriction 
endonuclease employed. Technical problems, which may arise, affect the $\lambda$ standard markers equally and so defective blots may be easily identified.

Two bands were observed in the preparations obtained from all the strains examined and these were of the lowest molecular size at approximately 0.4 and 0.6 kilobase pairs $(\mathrm{kbp})$. It is possible that these bands results from hybridisation of the probe to a number of poorly resolved bands of similar size. The remaining DNA detected by the probe gave rise to polymorphic restriction fragments. Each pattern consisted of several intense bands and a number of faint bands. At least a proportion of the less intense bands are likely to result from hybridisation to fragments which overlap the probe sequences. Some hybridisation to sequences with more distant homology with the probe may also occur at the low levels of stringency employed in these studies.

In most cases the RFLP type of a strain can be determined from the molecular sizes of the bands generated as calculated from the $\lambda$ molecular weight standards in the adjacent track. This is illustrated by the data shown in fig. 1, which shows a group of strains identified as being of RFLP type 1 by analysis of different typing blots. Restriction fragments from these isolates separated by electrophoresis in adjacent tracks of a single gel were indistinguishable. In some instances however, it can be useful to analyse DNA from strains thought to be indistinguishable, when compared on different gels, in adjacent tracks of a single gel because in some instances inter-strain pattern differences could be relatively difficult to identify. For example, patterns 7 and 27 differ from one another only in the positioning of a single band at either $4.8 \mathrm{kbp}$ or $5.1 \mathrm{kbp}$ respectively. The resulting difference in mobility is small and, consequently, isolates of these types can be reliably distinguished only if they are run in adjacent tracks of a gel.

Interestingly, RFLP types 5 and 26 as well as types 14 and 19 differ from each other in the presence or absence of a band at $22.5 \mathrm{kbp}$. The relative intensity of this band in the eight isolates of RFLP type 26 was variable. Evidence that this variation resulted from differences between strains and was not caused by unreproducible isolation, transfer or hybridisation of this fragment is available. Examination of repeated isolates (see Materials and methods, section $\mathrm{Bi}$ ) of strains LC185 and LC190 (RFLP type 26), which carry the $22 \cdot 5-\mathrm{kbp}$ fragment, gave reproducible patterns with the $22 \cdot 5-$ $\mathrm{kbp}$ band showing strain dependent intensity. The presence or absence of a band of this size is unlikely to be due to a simple difference in DNA sequence between the relevant groups of strains; if this were the case, its appearance in types 19 and 26 would be accompanied by a loss of bands in the corresponding types (14 and 5). The $22 \cdot 5-\mathrm{kbp}$ band may represent hybridisation of the probe to extrachromosomal DNA present in the strains having the $22 \cdot 5-\mathrm{kbp}$ band. This DNA is unlikely to be a circular form because both plasmid-bearing and plasmid-free strains are of the relevant RFLP types, and none of the plasmids examined hybridised with the probe sequence.

The discrimination of the RFLP typing method, as judged by its numerical index of discrimination, is excellent. Despite this, some evidence that the discrimination of the method is underestimated, due to the necessarily arbitrary designation of strains as 'related' or 'unrelated', can be adduced. Firstly, two unique RFLP types (types 30 and 33) were identified among the isolates designated as 'related' to one or more of the 'unrelated' strains; and secondly, the use of mainly clinical isolates may bias the sample towards those strains that most commonly cause infection. It would be interesting to study a larger number of environmental isolates collected from different geographical locations or environmental niches over an extended period.

Many of the strains which appeared to be epidemiologically unrelated gave different patterns of restriction fragments with the probe. However, groups of isolates from widespread geographical locations had indistinguishable patterns. For example, the three strains of RFLP type 3 were from the UK, USA and Czechoslovakia. If the absence of RFLPs corresponds to a very close genetic relationship between isolates, it seems likely that considerable dispersal of $L$. pneumophila strains of these types has occurred. In further support of this hypothesis is the evidence that several strains isolated from different locations shared not only the same RFLP type (type 1) and MAb subgroup (Philadelphia) but also a plasmid of $c .98 \mathrm{Mda}$ (data not shown).

Examination of epidemiologically associated strains showed that the patterns obtained were indistinguishable. This was demonstrated for a series of five groups of strains as follows: (a) seven isolates from patients involved in an outbreak of LD at the Stafford District General Hospital in 1985, which were of type 25 (fig. 3); (b) two isolates from individuals infected while staying in a Yugoslavian hotel, which were of type 24 (fig, 3); (c) nine isolates, of which four were clinical and five environmental, from an outbreak of LD at a Dutch hospital, which were of type 26 (in this case the 
22.5-kbp band was of similar intensity for each strain); (d) eight clinical isolates from an outbreak of $\mathrm{LD}$ at the British Broadcasting Corporation, Portland Place, London, which were of type 5; and (e) two isolates from an outbreak of LD at Lostock, Bolton, which were of type 5. In each of these cases the related strains also belonged to the same MAb subgroup.

An illustration of the use of this typing method is shown in tracks 3 and 4 of fig. 3. These patterns (RFLP type 8, of which these strains are the only representatives) were obtained with the strains isolated from two UK residents from different geographical regions who had stayed in the same hotel in Portugal within the incubation period of their illness. The strains were also of the same MAb subgroup. Epidemiological investigations have implicated this hotel as a source of 19 cases of LD in British tourists over a period of 7 years (Dr C. L. R. Bartlett, personal communication). The typing data support the hypothesis that the hotel or its environs was the probable source of infection.

In the outbreak of LD at the British Broadcasting Corporation, the typing method was used to examine six environmental isolates from the water system of the building at the centre of the epidemic. Three of these strains were of type 1, one of type 25 and two of type 5 (the outbreak type). MAb subgrouping revealed that two strains, one of type 1 and one type 5, were of the outbreak subgroup.

\section{REFERENCES}

Badenoch J (Chairman) 1986 First report of the committee of inquiry into the outbreak of Legionnaires' disease in Stafford in April 1985. Cmnd 9772. HMSO, London.

Bartlett C L R, Macrae A D, Macfarlane J T 1986 Legionella Infections. Edward Arnold, London.

Benson R F, Thacker W L, Wilkinson H W, Fallon R J, Brenner D J 1988 Legionella pneumophila serogroup 14 isolated from patients with fatal pneumonia. Journal of Clinical Microbiology 26: 382 .

City of Westminster Department of Environmental Services 1988 Broadcasting House Legionnaires' Disease : Report of the Westminster Action Committee convened to coordinate the investigation and control of the outbreak of Legionnaires' Disease associated with Portland Place, London W1 in April/May 1988. Chairman: Dr D. Cunningham.

Harrison T G, Taylor A G (eds) 1988 A laboratory manual for Legionella. J Wiley and Son, Chichester.

Hunter P R, Gaston M A 1988 Numerical index of the discriminatory ability of typing systems: an application of Simpson's index of diversity. Journal of Clinical Microbiology 26: 2465-2466.

Joly J R, McKinney R M, Tobin J O, Bibb W F, Watkins I D, Ramsay D 1986 Development of a standardized subgrouping scheme for Legionella pneumophila serogroup 1 using monoclonal antibodies. Journal of Clinical Microbiology 23: 768-771.
Thus only one strain, which was isolated from the part of the water system suspected as the source of infection was indistinguishable from the clinical outbreak strain by both RFLP typing and MAb subgrouping. This example illustrates the value of incorporating both RFLP typing and MAb subgrouping to increase the discrimination between L. pneumophila serogroup 1 strains. In many instances the two typing methods are complementary. However, an important advantage of RFLP typing over MAb subgrouping is that it may be applicable, without modification, to isolates of all serogroups of $L$. pneumophila. We have preliminary evidence that unrelated strains of serogroups $3,6,8$ and 14 can be distinguished on the basis of their RFLPs (results not shown).

The evaluation of the RFLP typing method presented here shows that it has excellent discrimination and reproducibility. Interpretation of the results obtained is relatively straightforward allowing comparison and monitoring of large numbers of isolates. Furthermore the analysis of RFLPs gives some indication of the genetic relationship between strains. It will be of interest to monitor the performance of the system under field conditions.

We are grateful to Drs C. L. R. Bartlett and S. McNamara from CDSC, Colindale, for providing epidemiological data and to all our microbiologist colleagues who submitted strains to us for examination.

Kado C I, Liu S T 1981 Rapid procedure for detection and isolation of large and small plasmids. Journal of Bacteriology 145: 1365-1373.

Owen R J, Borman P 1987 A rapid biochemical method for purifying high molecular weight bacterial chromosomal DNA for restriction enzyme analysis. Nucleic Acids Research 15: 3631 .

Rowbotham T J 1983 Isolation of Legionella pneumophila from clinical specimens via amoebae, and the interaction of those and other isolates with amoebae. Journal of Clinical Pathology 36: 978-986.

Saunders N A, Kachwalla N, Harrison T G, Taylor A G 1987 Typing of Legionella pneumophila for epidemiological studies using DNA probes. In: Fleurette J et al. (eds) Colloque Legionella. Collection Foundation Marcel Merieux, pp 197-203.

Saunders N A, Kachwalla N, Harrison T G, Taylor A G $1988 a$ Cloned nucleic acid probes for detection and identification of legionellae. Analytical Proceedings 25 : 128-129.

Saunders N A, Harrison T G, Kachwalla N, Taylor A G $1988 b$ Identification of species of the genus Legionella using a cloned rRNA gene from Legionella pneumophila. Journal of General Microbiology 134: 2363-2374.

Selander R K et al. 1985 Genetic structure of populations of Legionella pneumophila. Journal of Bacteriology 163: 10211037.

van Ketel R J, ter Schegget J, Zanen H C 1984 Molecular epidemiology of Legionella pneumophila serogroup 1. Journal of Clinical Microbiology 20: 362-364. 